\title{
A FUNÇÃO DAS REPRESENTAÇÕES SOCIAIS PARA PRÁTICAS PEDAGÓGICAS
}

\author{
THE ROLE OF SOCIAL REPRESENTATIONS FOR EDUCATIONAL PRACTICES
}

Aguinaldo Pereira - Instituto Federal de Mato Grosso - aguinaldo.pereira@cfs.ifmt.edu.br

Adriane Mendes de Souza - Secretaria de Estado de Educação do Distrito Federal - adrimendes@hotmail.com

\begin{abstract}
Resumo: Este artigo apresenta o processo construtivo de representações sociais e procura demonstrar como as colaboradoras (professoras de português do ensino público do Distrito Federal), reunidas em grupo focal, fundamentam suas representações sobre o uso da norma-padrão da língua portuguesa e sobre a função docente que exercem. O objetivo é verificar a força dessas representações em suas práticas pedagógicas. O quadro teórico desse estudo pressupõe interdisciplinaridade entre a sociolinguística interacional, a análise do discurso e a psicologia social. Essas áreas de estudo apresentam uma concepção similar sobre a linguagem como processo de interação em uso efetivo, na perspectiva de ação social.
\end{abstract}

Palavras-chave: representações sociais, norma-padrão, ensino de português.

\begin{abstract}
This article presents the constructive process of social representations and seeks to demonstrate how the collaborators, Portuguese teachers from public schools of the Federal District, gathered in focus group, establish their representations regarding the use of standard Portuguese, as well as regarding the teaching function they fulfill. The objective is to verify the strength of these representations in their teaching practices. The theoretical framework of this study presupposes interdisciplinarity between sociolinguistics, discourse analysis and social psychology. These areas of study present a similar conception about language as an interactive process in actual use, in the perspective of social action.
\end{abstract}

Keywords: social representations, standard language, Portuguese teaching.

\section{INTRODUÇÃO}

O intuito de assegurar que haja mudanças sociais positivas por meio da educação determina que sejam percebidos os processos simbólicos revelados na interação educacional. Explicando melhor, para que a pesquisa na área educacional possa produzir resultados mais substanciais, é necessário incorporar "um olhar interacional", um estudo voltado à subjetividade do sujeito e à relação dessa subjetividade com o mundo social.

Vygostsky (2007) afirma que funções mentais superiores organizam o mundo real, sendo mediadoras entre o sujeito e o objeto do conhecimento. Para o autor, essas funções são socialmente formadas e culturalmente transmitidas. Ou seja, por meio da troca com outros sujeitos, o conhecimento é internalizado, e papéis e funções sociais são definidos, permitindo, assim, a formação da própria consciência.
Trata-se, portanto, de um processo que parte do plano social - relações interpessoais - para o plano individual interno - relações intrapessoais.

Consoante ao pensamento de Vygotsky, Bakhtin (1995) defende que a personalidade que se manifesta pela projeção interior do sujeito é o resultado da inter-relação construída socialmente. Assim, discorre que as faculdades psicológicas e as expressões do sujeito formam-se no espaço social, desde o caminho percorrido nos processos mentais até a sua materialização exterior.

Dessa forma, quando uma manifestação mental se concretiza como enunciado em determinado contexto comunicativo, ela reflete a orientação social a que se encontra subordinada, em complexa adaptação do uso ao ambiente e aos interlocutores reais.

$O$ interesse investigativo em relação às representações de atores envolvidos no processo de ensino-aprendizagem de 
português fundamenta-se na expectativa de compreender como se estabelece a realidade escolar dessa disciplina a partir da visão que o professor tem das normas que compõem a língua e da função social exercida por eles.

$\mathrm{Na}$ busca por uma compreensão mais ampla do processo educacional, os estudos de representações sociais demonstram ser um caminho promissor para obter bons resultados, pois evidenciam a atuação do imaginário social sobre pensamentos e ações de pessoas e grupos, permitindo que reflexões sejam estimuladas. É essencial, assim, a pretensão de investigar como se formam e como entram em funcionamento os sistemas de referência utilizados pelos professores para interpretar os acontecimentos e ações que permeiam suas práticas pedagógicas. Isso ocorre porque, nesse procedimento, o docente confere significado às próprias ações rotineiras do ambiente escolar.

Na concepção de Moscovici (2007), quando é necessário estabelecer intercâmbio entre o mundo simbólico e os objetos, as representações assumem função importante no plano de construção da realidade. As representações são uma tentativa constante de equilíbrio entre um objeto externo que se insere pela primeira vez em nosso campo de visão e o nosso universo interior.

A partir das postulações iniciais de Moscovici (2007), o conceito de representação veio demonstrar que, para penetrar no universo do sujeito ou do grupo, certo objeto passa por uma série de relações, articulações e movimentações com outros objetos já existentes. Além disso, assimila propriedades e as acrescenta às próprias, transforma e é transformado por esse movimento.

Por apresentar estreitas relações com a linguagem, com a ideologia, com o imaginário social e principalmente por desempenhar relevante papel na organização da maneira de agir nas práticas sociais, o estudo das representações constitui elemento essencial à análise dos mecanismos que produzem interferência nos efeitos do processo educativo.

A ampliação do interesse pelo papel do simbólico na instrução das ações humanas parece ter auxiliado uma abertura de espaços para o estudo das representações sociais. Verificamos que, em anos recentes, um vasto número de trabalhos de pesquisa surgiu nessa área. É possível afirmar que o estudo pioneiro de Moscovici (2007) constituiu-se em um novo paradigma na psicologia social, pois projetou as bases conceituais e metodológicas que desenvolveriam os debates e os aprofundamentos subsequentes.

\section{Metodologias qualitativas}

Métodos e teorias qualitativas constituem os fundamentos da pesquisa desenvolvida. A escolha pela abordagem qualitativa deve-se à busca pela interpretação em oposição à mensuração quantitativa. O ponto central das investigações qualitativas é compreender os significados atribuídos pelos sujeitos às suas ações.

Por meio de técnicas etnográficas - caracterizadas pela interação com o pesquisado e pela formação de grupo focal -, fundamentamos a descrição das ações e representações dos atores sociais de modo a reconstruir sua linguagem e interpretar o discurso e os significados criados e recriados no dia a dia do fazer pedagógico de cada um. Além disso, dadas as características da etnografia, a ênfase ocorreu no processo da pesquisa e não nos resultados finais. O interesse maior voltou-se para o significado, para a maneira como os participantes veem a si mesmos, as suas experiências e o mundo que os cerca.

Coube aos pesquisadores a tentativa de apreender e retratar a visão dos colaboradores, os significados atribuídos por eles às suas ações e interações. Nesse processo, para que as transcrições traduzissem o ponto de vista dos atores, procurou-se ser fiel aos relatos e à reflexão conjunta. Ainda que os dados passem pelo filtro subjetivo do pesquisador, temos consciência de que, na busca das significações do outro, é necessário ultrapassar nossas próprias crenças e valores, admitir outras visões e concepções de mundo e voltar-se para os valores e os significados culturais dos pesquisados.

\section{A ATUAÇÃO NAS PRÁTICAS SOCIAIS}

A teoria das representações sociais baseia-se no conhecimento do homem sobre si mesmo, suas ações e manifestações na vida da organização social cotidiana.

Goffman (2009) utiliza o termo representação para se referir a toda atividade que ocorre em um período marcado pela presença constante de um ator social diante de um grupo particular de observadores em que exerce alguma influência. Além disso, designa como fachada a expressividade - do tipo padronizado - utilizada pelo sujeito durante sua representação proposital ou inconsciente.

Goffman (2009) observa que nas ações cotidianas os observadores fundamentam-se em estereótipos, facilitando o convívio social. Não se mantêm distintos padrões e expectativas de respostas para cada ator e representação, ligeiramente diferentes das experiências vivenciadas. Pode-se, em vez disso, fixar a situação em uma ampla categoria: nela se encontram convencionados os saberes anteriores acionados para acomodação da disposição atual.

Moscovici (2007) defende que uma ideia ou objeto, ao serem comparados com um paradigma de determinada categoria, assumem traços desta e são remodelados para se enquadrarem a ela. Garante-se, assim, minimamente, 
coerência entre aquilo que se conhece e aquilo que é desconhecido, em processo de ancoragem para classificar e nomear o novo.

Ainda segundo Moscovici (2007), coisas que não suportam classificação ou nome são esquisitas e intimidadoras. Por isso se experimenta resistência ou distanciamento quando não se consegue avaliar nem descrever algo para si próprio ou para os outros. Classificar constitui, assim, um processo de comparação com determinado protótipo.

Foucault (1999, p. 53) observa que outrora a linguagem associava-se imediatamente às coisas que ela nomeava. Além disso, assegura que, se na atualidade essa realidade não é mais posta, não significa que por isso a linguagem esteja "[...] separada do mundo; continua, sob uma outra forma, a ser o lugar das revelações e a fazer parte do espaço onde a verdade, ao mesmo tempo, se manifesta e se enuncia".

Foucault (1999, p. 137) estabelece que o cerne da representação está no ato de nomear:

Nomear é, ao mesmo tempo, dar a representação verbal de uma representação e colocá-la num quadro geral. Toda a teoria clássica da linguagem se organiza em torno desse ser privilegiado e central. Nele se cruzam todas as funções da linguagem, pois é por ele que as representações podem vir a figurar numa proposição.

Dessa maneira, pode-se afirmar que transformações sociais só se tornam possíveis quando há mudança nas representações.

Usando uma metáfora teatral, Goffman (2009) afirma que um indivíduo desempenha papéis sociais e, ao fazê-lo, requisita de seus observadores a atribuição de seriedade à impressão da realidade mantida perante eles. Ou seja, os atores desejam que os espectadores acreditem no personagem visto e nos atributos que aparentam possuir.

Contudo, pode acontecer de o ator não estar completamente convencido de sua prática. Essa possibilidade é aceitável, uma vez que ninguém está em melhor condição de observar e avaliar o espetáculo do que aquele que o encena.

Adicionado a isso, algumas vezes o ator pode conduzir a convicção de seu público para atingir determinada finalidade, sem se interessar pela opinião dos outros a seu respeito, ou a respeito da situação. O sujeito que assim age, sem acreditar na própria atuação e sem se interessar pela crença de seu público, pode ser denominado cínico, sendo o termo sincero reservado àqueles que creem na representação gerada por sua encenação (GOFFMAN, 2009).

Ainda segundo esse autor, o desempenho que os atores apresentam diante dos outros tenderá a incorporar e a exemplificar os valores oficialmente reconhecidos pela comunidade. A prática ressaltante desses valores oficiais - mais que a própria ação individual - está relacionada à maioria das sociedades estratificadas tendentes a idealizar padrões sociais dos estratos elevados. Essa idealização é reflexo da busca de posições mais elevadas por aqueles que ocupam posições subalternas.

Esse desejo não se aplica apenas à ocupação de certo lugar de prestígio social, mas também ao posto venerado dos valores socialmente sacramentados. A movimentação em direção ao ápice da pirâmide social requer atuações em conformidade com as expectativas dos ocupantes desse local, bem como esforços para galgar os degraus sociais, lutas para evitar a descida e sacrifícios adotados para preservar a fachada (GOFFMAN, 2009).

Quando enfatiza o uso de certa norma de linguagem disseminada e prestigiada pela classe dominante dentro da sociedade, o discurso docente expressa essa representação como ideal a ser perseguido pelos alunos. O domínio de determinada norma que, para o inconsciente coletivo, representa instrumento de acesso e permanência junto à elite constituída, torna-se impositivo pela força da representação.

O excerto abaixo, gerado a partir da entrevista com as professoras colaboradoras desta pesquisa, exemplifica com bastante propriedade a presença dessa representação:

ANITA1: "Aí eu falo pra eles não adianta eu, eu usar é, é esses termos assim pro... que vocês vão chegar lá no na, na, no... no PAS o ano que vem, que eu dou aula pra oitava série, vocês vão chegar no PAS, vocês vão... as provas, elas não vão vir assim com essa le... com essa linguagizinha aguinha com açúcar que vocês tão acostumados".

TARSILA: “Mas é aí que eu penso, viu? É... porque em relação a sua pergunta, que eu respondo que nós não podemos também... nos resumir ao que eles já sabem, nós temos que especular a curiosidade, levar, especular a curiosidade deles e aí que entra a questão quando eu falo pra eles: gente, cadê o dicionário?".

No excerto selecionado, o uso de linguagem não representativa da maioria da população configura-se como mecanismo de seleção - aquilo que permite a entrada nas universidades e órgãos públicos -, estabelecendo quem tem condições de iniciar a escalada rumo às posições superiores da sociedade.

\footnotetext{
1 Por recomendações éticas, os pesquisadores devem remover o quanto antes informações que possam ser utilizadas para identificar os colaboradores, preservando-os. Assim, as identidades das professoras encontram-se resguardadas pelo uso de pseudônimos de pintoras famosas, a saber: Tarsila do Amaral, Anita Malfatti, Frida Kahlo e Fani Bracher. Essa escolha deu-se pela representação que permite associar o ofício de ambas as profissões envolvidas, pois assim como as pintoras procuram expressar o universo pessoal pela arte, colocando sobre telas todo o colorido que extraem da relação com o mundo, as participantes deste estudo mostram-se empenhadas, pela arte educacional, em tornar o mundo mais bonito e melhor para se viver. A escolha foi negociada com as participantes.
} 


\section{CONSTRUÇÃO DISCURSIVA DAS REPRESENTAÇÕES SOCIAIS: DIÁLOGO COM MÚLTIPLAS CIÊNCIAS}

O estudo interdisciplinar na investigação de representações justifica-se pela dificuldade em estabelecer fronteiras distintas em pesquisas dessa natureza e pela possibilidade complementar de ampliar a análise do objeto pesquisado. Dessa forma, para o objetivo que pretendemos alcançar, propomos um diálogo entre a sociolinguística interacional, a análise do discurso e a psicologia social.

A aproximação das áreas citadas acima se deu porque elas entendem que a língua constrói e reconstrói a realidade em processos interativos, levando em conta a relevância do contexto onde essa interação acontece.

A união de vários campos teóricos complementares tem caracterizado a prática de pesquisas qualitativas em que este trabalho se encaixa, e justifica-se pela abrangência e profundidade almejadas nas análises que se fundamentam em diferentes ramos do saber.

Quanto à sociolinguística interacional, segundo Bortoni-Ricardo (2005, p. 147), “[...] trata-se de um paradigma de base fenomenológica, interpretativista, que apresenta um arcabouço teórico interdisciplinar e uma metodologia bastante refinada para a descrição dos fenômenos da interação humana", uma vez que envolve relações entre linguagem, sociedade e cultura. Seguindo essas bases teóricas, a organização social dos significados ocorre por meio de interação, em processos de negociação.

A análise do discurso, em consonância com a sociolinguística, na concepção de Dijk (2008, p. 17), compreende que "[...] os discursos são produzidos e recebidos por falantes e ouvintes ${ }^{2}$ em situações específicas, dentro de um contexto sociocultural mais amplo". Para o autor, o discurso não se concretiza em um simples fenômeno cognitivo, mas em uma interação que abrange o social e a cognição, sendo que as representações se constituem por atos discursivos.

Ratificando a visão de Dijk, Fairclough (2008) apresenta as práticas discursivas como elementos que produzem e transformam a sociedade (as identidades sociais, relações sociais, sistemas de conhecimento e crenças), sendo a constituição dos indivíduos como sujeitos, no processo de interação com os outros, realizada por meio do discurso.

Em articulação com os dois campos apresentados, utilizamo-nos ainda da psicologia social. O objeto dessa área é a investigação dos processos simbólicos emergentes

2 Os termos falante e ouvinte não são os mais apropriados para estudos sociointeracionais por limitar a interação à cadeia da fala e por designar papéis estáticos para interlocutores. Utilizamos, por isso, outros termos, como interagentes. na interação dos sujeitos no que diz respeito à construção e ao funcionamento dos sistemas de referência. Estes são ativados na classificação de pessoas e grupos quando se interpretam os fatos da realidade cotidiana.

Ressaltamos, ainda, que na interface do psicológico com o social, o estudo das representações desperta interesse das seguintes áreas das ciências humanas: sociologia, antropologia e história. Isso permite vinculá-lo com a ideologia, os sistemas simbólicos e as ações sociais. Essa multiplicidade de conexões com outras disciplinas próximas gera, para o tratamento psicossociológico das representações, o que se configurou de transversalidade ${ }^{3}$. Trata-se da capacidade de atravessar e dialogar com múltiplas áreas do estudo científico.

Na análise de Foucault (1999, p. 388), a representação não é constituída meramente como objeto das ciências humanas, "[...] pois ela é, como se acaba de ver, o próprio campo das ciências humanas, e em toda a sua extensão; é o suporte geral dessa forma de saber, aquilo a partir do qual ele é possível"

\section{RELAÇÕES DISCURSIVAS E PSICOSSOCIAIS: ALIMENTOS DE PRÁTICAS COTIDIANAS}

Aqui, a questão que surge na condução deste estudo é: o que entendemos por "representações sociais" ? Na convivência diária do sujeito com a comunidade a que ele pertence, as pessoas constantemente se confrontam com um vasto número de informações. Os temas e acontecimentos apresentados como algo novo no interior da comunidade geralmente passam a exigir - por fazer parte do convívio das pessoas e afetá-las de alguma maneira - que haja esforço na busca pela percepção de seus significados. Por meio de palavras já inseridas em seus repertórios, o novo torna-se familiar àquilo que já foi incorporado à memória.

Cotidianamente, nas conversas estabelecidas em casa, no trabalho ou com os amigos, apresentam-se situações em que é necessária a manifestação sobre fatos, elaboração de explicações, manifestação de julgamentos e declaração de posições. Essas interações sociais vão construindo os chamados "universos consensuais". Dentro deles, novas representações se formam e são comunicadas, de maneira que começam a integrar as ações sociais como autênticas "teorias" do senso comum - criações estruturais válidas para a complexidade do novo objeto, facilitando a comunicação

3 Segundo Guattari (2004, p. 111), "a transversalidade é uma dimensão que pretende superar os dois impasses, quais sejam o de uma verticalidade pura e de uma simples horizontalidade". Transversalidade define-se, assim, como extensão dialógica em diferentes níveis e sentidos das múltiplas ciências que compõem os processos teóricos que alicerçam essa pesquisa. 
e orientando as condutas. Essas "teorias" ajudam a moldar a identidade e o sentimento de pertencimento do ser ao grupo.

Para Moscovici (2007), a estrutura de determinada representação é composta por duas faces indissociáveis: uma figurativa e outra simbólica. Dessa maneira, a toda figura associa-se um sentido; e a todo sentido, uma figura. Além disso, esses processos acontecem por meio dos mecanismos denominados de objetivação e ancoragem. A atribuição de sentido a determinada figura abstrata, ou a materialização de certo objeto abstrato, foi chamada de objetivação. A atribuição de contexto que permita a interpretação desse objeto foi chamada, por sua vez, de ancoragem. É através da ancoragem que a representação desvela seu caráter essencialmente social.

Moscovici (2007) caracteriza o processo de objetivação como a materialidade de um objeto abstrato e, portanto, um dos maiores mistérios do pensamento e da fala. Ou seja, trata-se da capacidade de transformar determinada representação em realidade, fazendo da palavra que substitui a coisa, a coisa que substitui a palavra. Esse aspecto é altamente explorado por políticos e intelectuais com o objetivo de dominar as massas.

Jodelet (1988) apresenta três fases para o processo da objetivação. Na primeira, há a seleção dos elementos da teoria em decorrência de critérios culturais. Na segunda, há a formação de núcleo figurativo a partir dos elementos selecionados - estrutura imaginante responsável por reproduzir a estrutura do conceito, espécie de guia de leitura do mundo real. Na última fase, há a naturalização dos elementos do núcleo figurativo. Os elementos do pensamento se tornariam parte da realidade ou referentes para o conceito, um código comum, portanto, que permitiria classificar pessoas e acontecimentos, estabelecer comunicação com uso da mesma linguagem e, desse modo, influenciar os outros.

Já o processo de ancoragem não apenas expressa relações sociais, mas também contribui para sua constituição, pois integra, cognitivamente, o objeto representado com o sistema de pensamento social preexistente para a elaboração de novas representações. Contudo, a representação sempre se constrói sobre algo já pensado, manifesto ou latente. Desse modo, a capacidade de tornar familiar o que era estranho pode, com a ancoragem, propiciar a manutenção de quadros antigos de pensamento. Pode propiciar, ainda, a manutenção de posições preestabelecidas pelo uso de instrumentos como classificação, categorização e rotulação, uma vez que classificar, comparar e rotular supõem julgamento "teórico" sobre o objeto classificado.

Assim, o imaginário dos sujeitos que compartilham a mesma condição ou experiência social se estabelece, e eles expressam, nas representações, o sentido que dão às suas práticas coletivas. Para isso, usam sistemas de códigos e interpretações gerados socialmente, propagando valores, expectativas e pretensões em relação à sociedade.

Na concepção foucaultiana, o perfil histórico de uma época, designado a priori, é responsável pelas associações possíveis de compartilhamento, definindo as teorias construídas no universo comum das pessoas e a veracidade do discurso:

Esse a priori é aquilo que, numa dada época, recorta na experiência um campo de saber possível, define o modo de ser dos objetos que aí aparecem, arma o olhar cotidiano de poderes teóricos e define as condições em que se pode sustentar sobre as coisas um discurso reconhecido como verdadeiro. (FOUCAULT, 1999, p. 177).

Assim, pode-se afirmar que o fato de se compartilhar uma mesma condição social - acompanhado de um vínculo específico com o mundo, de valores, modelos de vida, constrangimentos e desejos - constituiria uma representação arraigada à expressão de solidariedade, de afirmação e de engajamento coletivo necessário à defesa da identidade social.

Na concepção de Moscovici (2007), os sujeitos em processos interativos, contextualmente situados, manifestam capacidades inventivas, afirmações, explicações e conceitos construídos no cotidiano referentes a qualquer objeto, social ou natural. O objetivo é torná-lo familiar e garantir a comunicação no interior do grupo a que pertencem.

Dessa forma, conhecendo a história de uma formação social, bem como a postura dos atores envolvidos e as atitudes que historicamente tendem a assumir frente aos principais conflitos sociais, podem-se assinalar tendências de ações e, por meio delas, construir reflexões que levem os atores sociais das práticas à crítica de suas atitudes (decidindo quais devem permanecer e quais devem ser extintas).

\section{REPRESENTAÇÃO SOCIAL E IDENTIDADE}

Pela compreensão do processo de descrição sociológica do indivíduo, o foco desta pesquisa é a imagem representativa que o professor tem de seu trabalho e das normas linguísticas com as quais convive.

Segundo Pêcheux (2006), o homem, como ser político revestido de ideologia, tem na linguagem a forma substancial de processos ideológicos. Esse autor apresenta um argumento para a compreensão de ideologia quando a descreve, no meio social, como formas materiais, e não meramente como ideias incorpóreas.

Aliado à concepção althusseriana, Fairclough (2008, p. 52) define ideologia em relação à constituição dos sujeitos: 
[...] a ideologia funciona pela constituição (interpelação) das pessoas em sujeitos sociais e sua fixação em "posições" de sujeito, enquanto ao mesmo tempo lhes dá a ilusão de serem agentes livres. Esses processos realizam-se no interior de várias instituições e organizações, tais como a educação, a família ou o direito, que na concepção de Althusser funcionam como dimensões ideológicas do Estado.

Na busca da representação social constituída pelos pesquisados, faz-se necessário analisar alguns conceitos sobre a construção de identidade. Essas duas definições interligam-se formando uma totalidade complexa em que a representação é compreendida por processo cultural estabelecido dentro de identidades individuais ou coletivas.

Segundo Hall (2005, p. 31), apesar de caber à psicologia o estudo dos processos mentais do indivíduo, a crítica ao individualismo racional do sujeito cartesiano coube à sociologia. Situando-o dentro de um contexto coletivo de participação social, a sociologia:

[...] localizou o indivíduo em processos de grupo e nas normas coletivas as quais [...] subjaziam a qualquer contrato entre sujeitos individuais. Em consequência, desenvolveu uma explicação alternativa do modo como os indivíduos são formados subjetivamente através de sua participação em relações sociais mais amplas; e, inversamente, do modo como os processos e as estruturas são sustentados pelos papéis que os indivíduos neles desempenham. Essa "internalização" do exterior no sujeito, e essa "externalização" do interior, através da ação no mundo social [...], constituem a descrição sociológica primária do sujeito moderno e estão compreendidas na teoria da socialização.

Ainda segundo Hall (2005, p. 13), na pós-modernidade, a partir da primeira metade do século $X X$, observa-se o deslocamento do sujeito e das identidades de uma para diversas "posições de sujeito", algumas vezes contraditórias, como foi explicitado por esse autor:

O sujeito assume identidades diferentes em diferentes momentos, identidades que não são unificadas ao redor de um "eu" coerente. Dentro de nós há identidades contraditórias, empurrando em diferentes direções, de tal modo que nossas identificações estão sendo continuamente deslocadas [...]

\section{IDEOLOGIA E HEGEMONIA: BASES SOCIAIS REPRESENTATIVAS}

Considerando a característica transversal desse estudo, apresentamos aqui a articulação do conceito de representação com o sentido de ideologia de Althusser (2007) e de Gramsci (1978). Percebemos as representações como práticas discursivas e destacamos que sua transformação pode dar-se no plano das lutas hegemônicas que ocorrem na esfera pública e na correlação com o mundo individual.

Esquadrinhar o sustentáculo de uma representação pode levar-nos a descobrir que sua origem está muito distante e que pode relacionar-se com algum conflito histórico. Pode, ainda, demonstrar que essa representação possui certa funcionalidade dentro da sociedade. Ou seja, a representação pode estar a serviço de práticas hegemônicas que concorrem para a manutenção de determinada elite no controle do poder.

Althusser (2007) refere-se à ideologia em dois sentidos. Inicialmente, aborda a teoria da ideologia em geral, que estaria presente em toda sociedade humana independentemente de interesses particulares. Sua função é assegurar a coesão social por meio de um conjunto de ideias, conceitos, valores e visões de mundo compartilhadas. Essa teoria contrapõe-se à teoria das ideologias especificas, em que a primeira função é sobredeterminada pela segunda: assegurar a dominação de uma classe.

Esse segundo conceito de ideologia, baseado em Marx, seria, no entendimento altusseriano, uma das faces da ideologia. Antes dele, haveria outro terreno: o das ideias e representações da sociedade em geral, sobre o qual se formam e se assentam as influências e as manifestações das ideologias particulares. Assim posto, o aspecto sociológico e o aspecto político da ideologia ficariam vinculados ao papel determinante da constituição das identidades e dos sujeitos.

Para Althusser (2007), as ideias e visões de mundo dos sujeitos apoiam-se em suas práticas, estabelecem quais papéis são legítimos e quais são estigmatizados, estando à força da ideologia geral, centrada no seu caráter performativo. O fato de as crenças e representações, consolidadas no terreno da ideologia em geral, fundamentarem práticas, propicia que tais elementos estejam sujeitos a entrar no campo ideológico com o sentido das ideologias específicas.

As práticas dos sujeitos, fixadas numa relação coletiva, reproduzem ou transformam os sistemas sociais e, por isso, sustentam ou superam as relações de poder e o status quo das diferentes classes. Desse modo, os elementos que constituem a ideologia geral estariam predispostos a uma nova redefinição, consoante a atribuição de importância ideológica das classes sociais disseminadas pelos chamados Aparelhos Ideológicos de Estado, inseridos nas várias esferas da realidade cotidiana das vivências pública e privada, tais como igreja, trabalho, família etc. Pode-se afirmar, então, que os elementos constitutivos da ideologia em geral compõem a base das ideologias particulares.

Para Gramsci (1978, p. 377), a ideologia está socialmente generalizada, pois os homens não podem agir sem regras 
de conduta, sem orientações: ela "[...] é o terreno sobre o qual os homens se movimentam, adquirem consciência de sua posição, lutam". Contudo, ela é mais que um sistema de ideias, pois se relaciona à capacidade de inspirar atitudes concretas e orientar ações, outra vez evidenciando seu caráter performativo. Nesse ponto, defende-se que a prática hegemônica de dada ideologia dominante pode gerar uma visão de mundo supostamente mais coerente e sistemática, que não só influenciaria a população, mas também serviria como princípio de organização das instituições sociais.

É na ideologia e por meio dela que determinada classe pode exercer supremacia sobre as outras, isto é, pode assegurar adesão e consentimento das grandes massas. Aqui, destacam-se práticas pelas quais os sujeitos, em grupos sociais organizados, buscam adeptos para garantir a predominância de suas interpretações sobre o mundo e sobre as organizações sociais, inserindo-as nas práticas e rituais do dia a dia.

\section{DISCURSO E PERMANÊNCIA DE PODER}

A relevância desse tópico refere-se ao papel do poder disseminado nos discursos sociais em interação. Para o debate pretendido, o poder é explicado como propriedade das relações sociais. Ele se manifesta nos processos de interação quando ações concretas ou latentes de alguém, uma pessoa ou um grupo, impõem redução de liberdade social em relação a outrem.

Dijk (2008) ensina que, em contexto distinto daqueles onde ocorre o exercício do poder pela força física, o controle social diário é exercido sobre a cognição das pessoas a quem se pretende dominar. Esse controle das "mentes" dos sujeitos se dá pela supressão de informações ou opiniões indispensáveis para que possam elaborar ou realizar suas atuações.

Dessa maneira, grande parte do controle social que acontece nas sociedades ocidentais, na atualidade, ocorre por domínio cerebral persuasivo, por comunicações discursivas ou por resultado do medo de sanções impostas pelo grupo dominador, no caso de este não ter os seus desejos atendidos. Contudo, esse controle mental deixa brechas aos subjugados para que possam esboçar alguma liberdade e resistência.

Assim, no meio escolar, no ensino de português, a imposição de um estudo de língua desvinculado do real uso do aluno - estruturado no ensino de regras gramaticais e de norma-padrão abstrata - provoca reação de resistência. Conforme o relato das colaboradoras desta pesquisa, após serem obrigados a usar, nas aulas de português, um modelo linguístico que não faz parte do seu repertório natural, os alunos resgatam o uso de sua variedade espontânea nas aulas de outros professores e em suas interações, negando a prática daquilo que Ihes foi imposto.

FRIDA: "Então é prática, então qualquer coisa que eles falam, ou é um plural, ou uma coisa assim que... não caiu bem, então o 'a gente vamos' então, ele é terrível".

ANITA: "É".

FANI: "Nossa! Eu ia comentar sobre isso".

FRIDA: "É... vamos lá, volte para o seu lugar, aí você levanta de novo, vamos ver, volte primeiro, vai...".

Coord.: "Rebobinar".

FRIDA: "Rebobine, aí agora comece novamente, aí ele... começa e aí já... vai falando, pensando... se erra, aí não! Recomece. Até praticar mesmo, praticar o uso da língua, porque aí ele vai percebendo o...".

ANITA: "É".

FRIDA: "O que ele está falando, e agora? Agora eu posso, professora? Falei direitinho, professora? Falou. Então... só que não é toda hora que você pode fazer isso dentro de sala da aula, né?".

ANITA: "É, é".

FRIDA: "Dentro de sala".

TARSILA: "É, é exatamente aquela história, né? De você falar, eles aprendem, agora na hora de colocar a prática cadê a... a prática que eles não têm?".

FRIDA: "O feedback, é...".

ANITA: "É".

TARSILA: "Não é? E... pelo fato... só pra fechar, dele tá tão acostumado... ele acaba o que... usando o que tá todo mundo usando".

Dijk (2008) afirma que o poder pode ser intencional ou involuntário, exercido para manter ou ampliar a base de autoridade de determinado grupo predominante. O exerćício ou preservação do poder perpassa pela comunicação direta, por pedidos, comandos ou ameaças. Geralmente, envolve mais de uma forma de atuação, consistindo, na interação social, em consenso ou em contestação fundamentados ideologicamente. Esses fundamentos ideológicos alicerçam-se na cognição e são partilhados e relacionados para o interesse dos membros de certo grupo, sendo obtidos, validados ou alterados pelo discurso.

Para Dijk (2008), a ideologia e as práticas ideológicas dela derivadas são geralmente adquiridas, exercidas ou organizadas por meio de várias instituições; entre elas o Estado, os meios de comunicação, o aparato educacional, a igreja e a organização familiar. $\mathrm{O}$ autor alerta que, embora haja práticas e estruturas sociais que representam um papel importante na expressão, exercício ou reprodução da ideologia, não se pode afirmar que a ideologia seja essas 
práticas ou instituições, mas uma forma de cognição social.

Comumente, grupos dominantes tendem a ocultar sua ideologia, fazendo com que ela seja acatada como sistema de valores, normas ou objetivos gerais ou naturais incorporados à formação do consenso. Assim reproduzida, a ideologia e o poder que dela desponta assumem formato hegemônico na sociedade. Por essa análise, o autor concebe ideologia como uma estrutura complexa que controla a formação, a transformação e a aplicação de outras formas de cognição social, tais como o conhecimento, as opiniões, as posturas e as representações sociais.

O poder institui-se por recursos que permitem aplicar sanções. Esses recursos são representados por atributos ou bens socialmente valorizados e desigualmente distribuídos: riqueza, autoridade, conhecimento, privilégios, pertencimento a certo grupo etc.

Dijk (2008) ressalta que as circunstâncias essenciais e determinantes para a prática do controle social decorrente do discurso estabelecem-se pelo seu domínio e sua produção. Destaca, ainda, que cognições sociais ideológicas não se alicerçam em crenças ou opiniões individuais, mas, predominantemente, em representações de membros formadores ou instituições sociais. Estes reconstroem a realidade em conformidade com os interesses de quem controla os meios ou as instituições de produção e reprodução ideológica (meios de comunicação e instituições de ensino, por exemplo).

Assim, a crença - justificada por princípios socialmente relevantes - é base sobre a qual se estrutura a formação sociocognitiva da ideologia, falsa ou verdadeira. Esta também se ampara nos discursos, especialmente naqueles das instituições e dos grupos poderosos, capacitados para mediar e administrar essas crenças. As pessoas, por sua vez, apoiam seus discursos no poder das instituições a que estão vinculadas (DIJK, 2008).

Assim, em sala de aula, espera-se que a fala e as informações dos dominados ocorram apenas se solicitadas ou ordenadas, com produção controlada por elites e respaldada no poder simbólico ${ }^{4}$ de decidir e determinar debates, tópicos, estilo e formato do discurso.

No trecho abaixo, gerado por gravação em grupo focal, as colaboradoras deste estudo expõem como o controle do que pode ser dito e de como pode ser dito nas aulas de português reduz a produção discursiva do aluno na escola, espaço representativo do poder institucional do Estado: tal controle efetiva-se ao impor-se um modelo linguístico decidido pelo professor.

TARSILA: "Então eles tomam um susto muito grande quando chegam na escola... chegam à escola, e nós

4 Conforme Bourdieu (1989). trabalhamos... exigimos dele a linguagem formal, a língua portuguesa, não é? E... o que que eu percebo? Que tá muito distante deles, a língua que eles falam... e a língua formal".

ANITA: "A realidade...".

TARSILA: "A língua que deveriam falar".

FANI: "É completamente diferente...".

TARSILA: "Que deveriam usar. Então dá a sensação que eles tão aprendendo uma língua estrangeira".

ANITA: "É. É verdade!".

TARSILA: "A língua portuguesa, então... assim é...".

ANITA: "Eu sinto isso também".

TARSILA: "Ela deixa de ser materna, né? Porque, ué? Então o que eu falo não existe?"

ANITA: "É".

TARSILA: "Tanto que eles falam assim: 'Ah, professora, a senhora entendeu, né?'. Bom, aí nós vamos entrar em outro campo que é a questão da comunicação".

ANITA: "É".

TARSILA: "Existe a, hou... houve a comunicação? Você entendeu o que eu falei? O que você falou tem sentido? Tem. E o que nós observamos, né, FRIDA? Que ao elaborar uma resposta na prova... eles querem usar a linguagem formal, mas não sabem".

ANITA: "Humhum".

\section{REPRESENTAÇÕES SOCIAIS E ENSINO DA NORMA-PADRÃO}

A teoria das representações estudada pelo prisma da psicologia social situa-se na perspectiva do senso comum como verdadeira "teoria" coletiva sobre o real. Além disso, objetiva levar o estudioso a descobrir por que razão se criam representações ou se as empregam.

Moscovici (2007) e outros teóricos afirmam que a representação social constitui um saber desenvolvido no cotidiano das relações sociais, em que grupos de referência exercem forte influência na construção individual dessas representações. O autor observa que a representação social é uma preparação para a ação, não apenas na medida em que guia o comportamento, mas, sobretudo, por remodelar e reconstituir os elementos contextuais nos quais a ação deve ocorrer.

Dessa forma, representações sociais estabeleceriam o campo das comunicações possíveis, dos valores, das crenças, das atitudes ou ideias pertinentes e compartilhadas pelos grupos sociais, regendo quais as condutas desejáveis ou admitidas em determinado ambiente. 
Pelo exposto, surgiu o interesse em realizar esta pesquisa com professores de língua portuguesa de escolas públicas. Tal estudo nasceu da observação de que, em sua prática docente, esses professores são confrontados de forma constante com um desafio: o de proporcionar aos alunos das classes mais desfavorecidas a habilidade de se apropriarem da norma considerada padrão pela sociedade.

É importante observar que os estudos linguísticos geralmente destacam que um dos papéis institucionais da escola e do professor, principalmente daquele que trabalha com ensino de língua portuguesa, é a tentativa de ruptura com o ciclo da pobreza. Isso ocorre, porque, nos dias atuais, o aludido fracasso escolar das crianças pobres é a preocupação dominante no campo da educação. Dentro da visão sociolinguística do ensino, o comportamento linguístico é responsável pela estratificação social e manutenção do quadro de distribuição desigual de renda e de bens materiais e culturais (BORTONI-RICARDO, 2005).

O conceito de norma-padrão vem sendo objeto de análise de muitos estudos linguísticos. Há várias publicações com posicionamentos de estudiosos da linguagem em que se verifica a preocupação de abordar tal conceito como objeto de trabalho.

A pretensão desse estudo é demonstrar como as considerações e valorizações das variadas normas podem constituir instrumento direcionador para o trânsito do usuário da língua entre os diversos estratos sociais.

Faraco (2008) justifica a pertinência de discutir a noção de norma devido à percepção conservadora, elitista e excludente que ainda impera nas instâncias da vida social, nas salas dos professores e, inclusive, nas salas de aula. Embora fundamentada em concepções medievais, a noção de norma-padrão abstrata tomou o imaginário coletivo como sinônimo de língua e ainda é preponderante no meio escolar. Essa norma é responsável pela realização de um ensino tradicional, fundamentado em regras gramaticais obsoletas e distantes da realidade linguística contemporânea.

O autor defende a legitimidade de todas as normas e denuncia a perversidade do sistema linguístico baseado na suposição de um sistema unitário e homogêneo. Evidencia também o caráter político e excludente da escolha de determinada norma como símbolo de correção, pois isso torna as demais variedades preteridas, apontando-as como incorreção ou erro. Propõe, ainda, debate nacional sério sobre essas questões e preconiza a adoção de uma norma culta/comum/standard que se fundamente na variedade falada pelos letrados da sociedade brasileira dos centros urbanos, em situações de monitoramento (FARACO, 2008).

Diante das constatações dos estudos linguísticos sobre o caráter conservador do ensino de língua portuguesa
- o qual tem contribuído para a manutenção de uma sociedade desigual em termos de distribuição econômica e de oportunidades -, procurou-se investigar, junto a alguns atores sociais e professores de língua portuguesa, quais percepções, crenças, valores, atribuições e atitudes eles possuíam no desempenho de sua função.

Procurou-se investigar também quais expectativas eles mantinham com relação ao exercício do ensino-aprendizagem, pois o homem não vive isolado, mas se constitui essencialmente como ser social, inserido em contexto histórico e cultural definidos pela construção constante de valores. Estes, por sua vez, são analisados e julgados no domínio das memórias coletivas onde estão depositados os conteúdos culturais cumulativos da sociedade.

Constatar respostas individuais do sujeito significa, portanto, revelar tendências dos grupos a que ele pertence, naquilo que, na concepção de Bourdieu (1989), o campo social autoriza. Significa também observar a exteriorização da subjetividade que cria, recria e transforma a realidade social. As representações assim expostas pressupõem uma modalidade para o conhecimento de mundo que emerge das interações sociais engendradas no cotidiano que se pretende estudar.

No estudo aqui apresentado, a pesquisa associa-se à vontade de entender melhor a problemática de ensino da língua. Buscou-se, sobretudo, explicitar a necessária reflexão sobre as representações que convergem em ações reais nesse tipo de ensino. Para tanto, investigou-se a maneira e a razão que orientam e justificam essas percepções, crenças, valores, atribuições, atitudes e expectativas construídas e mantidas dentro de certo conjunto de significados socialmente cristalizados e repartidos entre os atores estudados.

\section{CONSIDERAÇÕES FINAIS}

Nesta breve revisão do campo de estudo das representações sociais, procuramos destacar, em paralelo aos seus aspectos teóricos, suas aplicações relacionadas à área da educação especialmente as possíveis contribuições de análise para o ensino-aprendizagem -, uma vez que esse modo de abordar o tema é uma sugestão que vislumbra caminhos propícios para compreender de forma mais ampla o processo educacional.

Duas intenções perpassaram o desenvolvimento deste trabalho. A primeira foi demonstrar que, embora haja muitas críticas relacionadas a estudos que se embasam em métodos qualitativos, a teoria das representações sociais oferece instrumentos extremamente úteis ao estudo da influência 
do imaginário social sobre o pensamento e as ações das pessoas e grupos. A segunda intenção foi evidenciar que as investigações dessa natureza visam à reflexão de professores e pesquisadores sobre as possibilidades facultadas por esse campo de estudo para a percepção dos sistemas simbólicos. Agindo no nível de grupos sociais e no nível macrossocial, esses sistemas afetam as interações cotidianas na escola, concorrendo para o bom desempenho escolar ou estabelecendo o fracasso no desenvolvimento do ensino-aprendizagem.

Fica explícito que o estudo das representações sociais sucede-se na união de suas duas faces, a simbólica e a material. Ou seja, não lidamos somente com objetos simbólicos ou subjetivos, mas também com a sua materialidade. Em primeiro lugar, na sua origem, tendo em vista seus componentes referenciais, os dados do mundo real - concretos ou conceituais -, nos quais as representações se fundamentam. Em segundo lugar, em sua atualidade e objetivação, ou seja, na forma como essas representações transformam-se em práticas, em ações, no modo como inscrevem-se nas relações sociais e repercutem de maneira concreta na vida das pessoas.

Essa última face revela, claramente, a dimensão social das representações: o fato de converterem-se em práticas (caráter performativo), tornando-se elementos objetivos e reais na sociedade. Aqui, ressalta-se que esse alcance é estabelecido sobretudo pela comunicação, que tem uma função indispensável nas transformações e nas interações constituintes do consenso social.

Evidentemente, quando certa representação torna-se objeto de pesquisa das Ciências Humanas, de alguma maneira ela já penetrou ou está penetrando no campo discursivo. Contudo, muitas vezes o máximo que se pode fazer é reconhecer como as representações, presentes em um momento histórico com sua forma peculiar de uso naquele momento, são ou podem ser colocadas a serviço de uma ideologia ou luta hegemônica.

Nos notórios enfrentamentos de classes, os valores e interesses são motivações. Porém, para que possam ocorrer, eles necessitam de uma matéria, de um repertório de significados e de referenciais comuns que possibilitem a comunicação. O conteúdo desse repertório, que Althusser (2007) denomina de ideologia em geral, será aqui assumido como representações sociais. Estas incluiriam desde representações mais antigas até as diretamente relacionadas com as concepções de ordem e organização social. E também as percepções sobre a posição dos sujeitos na organização, identificando a si e ao outro dentro de papéis, de categorizações dos indivíduos e dos grupos.
Na prática discursiva da esfera pública, em que há grupos em situação conflituosa ou com interesses comuns em busca de hegemonia, certos significados podem paulatinamente vencer e atingir relativa estabilidade, ou podem tornar-se hegemônicos. Assim, as representações sociais são transformadas, mas isso não significa que este seja o único meio de alterá-las, ou ainda que todas as representações, com seu caráter performativo, estejam a serviço das classes dominantes e do poder estabelecido.

A opção deste trabalho foi pensar as representações sociais como matéria comunicativa do cotidiano que estabelece uma perspectiva diferente às ações dentro da esfera pública e da luta hegemônica. Sua relevância está no fato de que são as representações, em última instância, que modelam as práticas diárias dos indivíduos. Desse modo, assim como no cotidiano, as representações teriam caráter performativo - direcionamento das ações e disposição do real. Ao adentrar o campo político, esse caráter performativo assume o sentido althusseriano: repercussão dos atos e do posicionamento dos sujeitos dentro das organizações sociais. Portanto, ao nível psicossocial do conceito de representações sociais, seria acrescentado também o nível sociológico.

Observando que os processos de comunicação social podem ser e geralmente são assimétricos, retoma-se a questão das desigualdades e diferenças sociais. Isso se dá tanto no sentido material - acesso a bens e recursos culturais e comunicativos -, como observado por Bortoni-Ricardo (2005), quanto no sentido simbólico de construção da identidade ou no posicionamento e reconhecimento dos indivíduos e grupos sociais entre si.

O ensino, entre outras funções, pretende propiciar ao aluno maior mobilidade social sem que, para isso, tenha que se cometer a violência simbólica de destituí-lo de sua variedade vernacular - responsável por sua identidade social dentro do grupo ao qual pertence. Se o conhecimento das representações sociais, dos professores colaboradores e da pesquisa puder ajudar a torná-los professores-pesquisadores de suas práticas e mais conscientes em um processo contínuo de reflexão sobre o papel que eles desempenham na construção de ensino, este trabalho já terá demonstrado sua utilidade.

\section{REFERÊNCIAS}

ALTHUSSER, L. Aparelhos ideológicos de Estado. 10. ed. Rio de Janeiro: Graal, 2007.

BAKHTIN, M. Marxismo e filosofia da linguagem. 9. ed. São Paulo: Hucitec, 1995. 
BORTONI-RICARDO, S. M. Nós cheguemu na escola, e agora? Sociolinguística e Educação. São Paulo: Parábola Editorial, 2005.

BOURDIEU, P. O Poder simbólico. Rio de Janeiro: Bertrand/ Difel, 1989

DIJK, T. A. van. Cognição, discurso e interação. 6. ed. São Paulo: Contexto, 2008.

Discurso e poder. São Paulo: Contexto, 2008.

FAIRCLOUGH, N. Discurso e mudança social. Brasília: Editora Universidade de Brasília, 2008 (reimpressão).

FARACO, C. A. Norma culta brasileira: desatando alguns nós. São Paulo: Parábola Editorial, 2008.

FOUCAULT, M. As palavras e as coisas: uma arqueologia das ciências humanas. 8. ed. São Paulo: Martins Fontes, 1999.

GOFFMAN, E. A representação do eu na vida cotidiana. 9. ed. São Paulo: Vozes, 2009.

GRAMSCI, A. Concepção dialética da história. Rio de Janeiro: Civilização Brasileira, 1978.

GUATTARI, F. A transversalidade (1964). In: Psicanálise e transversalidade: ensaios de análise institucional. Aparecida: Idéias \& Letras, 2004.

HALL, S. A identidade cultural da pós-modernidade. 10. ed. Rio de Janeiro: DP\&A, 2005.

JODELET, D. Representação social: fenômenos, conceitos e teoria. Rio de Janeiro: Fundação Getúlio Vargas, 1988.

MOSCOVICl, S. Representações sociais: investigações em psicologia social. 5. ed. Petrópolis: Vozes, 2007.

PÊCHEUX, M. O discurso: estrutura ou acontecimento. 2. ed. Campinas: Pontes, 2006.
VYGOSTSKY, L. S. A formação social da mente. 7. ed. São Paulo: Martins Fontes, 2007.

Recebido em: 22/04/2015

Aceito em: 06/05/2015 